\title{
sciendo METHANE SLIP DURING CARGO OPERATIONS ON LNG CARRIERS AND LNG-FUELED VESSELS
}

DOI 10.2478/ntpe-2018-0036

\author{
DSc. PhD. Eng. Jerzy Herdzik \\ Gdynia Maritime University, Poland
}

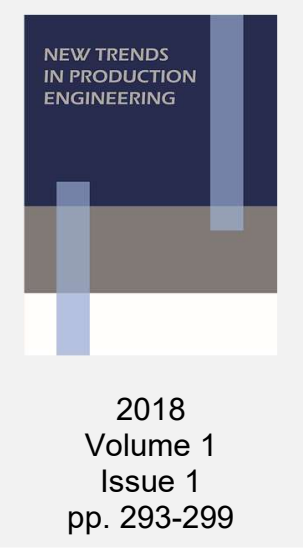

\begin{abstract}
In this paper was presented the problems of methane leakages during cargo operations on LNG carriers. Also the leakages are possible on LNG fueled vessels. Due to green-house effect from methane on the atmosphere it should be done some measures to avoid it. Building the cargo tanks with very high capacity, utilization of better thermal insulations limits the quantity of boil-off (BOG). It is used as a fuel in marine power plant, only the overage should be liquefied again. The leakages attend all cargo operations which methane goes directly to the atmosphere through pressure-vacuum valves and gas freeing installation to mast riser or by the ventilation system from cargo pump or compressor room. To minimize the slip on LNG carriers the re-liquefaction systems are installed. They are based on cooling systems which boil-off gas (mainly methane) is liquefied at ambient pressure in temperature about $161.5^{\circ} \mathrm{C}$ by pre-cooled nitrogen gas at temperature about $-180^{\circ} \mathrm{C}$. Compressed nitrogen to a pressure about $25 \mathrm{MPa}$ through multistage compressors with intercooling systems is expanded step by step (in intercoolers) to pressure about ambient reaches the temperature about $-180^{\circ} \mathrm{C}$. The re-liquefaction system needs delivering a lot of electric energy. The total level of methane leakages from mining to the last consumer may be different and sometimes very high. The leakage level starts as minimal $1 \%$ and may be raised up to $10 \%$. It was indicated the undertaken actions and next possibilities of methane slip limitations.
\end{abstract}

Keywords: Methane, methane slip, cargo operations, LNG carrier, LNG-fueled vessels

\section{INTRODUCTION}

Liquefied natural gas (LNG) is transported by sea by specialized vessels (LNG gas tankers) which are ready to carry cargo in cryogenic tanks in temperature about $-61.5^{\circ} \mathrm{C}$ and a little over ambient pressure (Mitsui OSK Lines, 2007, DeLancey, 2013). Due to the boil-off the LNG vapor is used as a fuel in dual-fuel diesel engines and boilers. The LNG is more and more used as marine fuel for other vessels. Based on the lower heating value the combustion of methane causes about $28 \%$ less $\mathrm{CO}_{2}$ compared to diesel fuel (methane has higher LHV and smaller carbon content).

Escaping methane leakage is called slip. It goes from a extracting well (Proceedings, 2016), during cleaning and liquefaction processes (Mokhatab, 2015), during transport and re-loading processes, any leakages, vessel bunkering operations, during engine misfire etc. It means that gaseous methane goes to the atmosphere increasing the greenhouse effect. The global warming potential (GWP) depends on the type of gas and time taking into account in comparison to carbon dioxide effect (Corbett et al, 2015). For methane the GWP coefficient (depending on time, accordingly 100 and 20 years) is from 25 to 72 (in other sources from 28 to 84 ).

\section{REASONS OF METHANE SLIP DURING CARGO OPERATIONS}

All cargo operations on LNG tankers should be carried on to minimize the methane slip to the atmosphere. The possibility of leakages is from (Hamworthy Gas Systems, 2006, Cargo Operating Manual, 2008, IMO, 2009, LNG Custody, 2001):

- gassing-up process of cargo tanks due to mix the inert gas with methane vapor;

- cooling process of cargo tanks with the use of liquefaction system;

- the cargo tanks through pressure-vacuum and safety relief valves to avoid the risk of pressure increasing over the permissible limit and tank rupture; 
- loading and unloading operations with a necessity of connecting and disconnecting the pipelines, the problems of exchanging the liquid and vapor among the vessel and terminal;

- boil-off in cargo tanks, should be taken off from cargo tanks to power plant engines (after preparing) as fuel and liquefaction systems of LNG;

- the liquefaction system in work during loading and ballast voyage;

- gas freeing of cargo tank to reach gas free certificate;

- fire following leakage of cargo;

- cargo connection rupture, pipeline fracture or cargo spillage;

- lifting of a cargo system relief valve (McGuire and White, 2008);

- LNG bunkering operations;

- misfire in dual-fuel or LNG engines.

The combustion of the gas in conventional or dual-fuel engines always creates some methane slip. Emissions of unburnt methane were around $7 \mathrm{~g}(0.7 \%)$ per $1 \mathrm{~kg} \mathrm{LNG}$ at high engine loads (near nominal), rising to $23-36 \mathrm{~g} \mathrm{(2.3-3.6 \% )} \mathrm{at} \mathrm{lower} \mathrm{loads} \mathrm{(European} \mathrm{Commission,} \mathrm{2016).} \mathrm{The}$ reason of slip increase could be due to slow combustion at lower temperatures, which allows some quantities of gas to avoid the combustion process. It can be minimized by discerning control. Possible ways of doing this involve carefully timing of the injection of pilot fuel (about $1 \%$ of marine diesel or gas oil MDO or MGO) to initiate the combustion. The next way is using the catalysts. They could be used to avoid (minimize) methane emissions.

It should be mentioned that emissions contained particles (particulate matters, PM). Although overall PM emissions were lower from LNG than MGO, but the PM emissions from LNG were dominated by very small and volatile particles (about $1 \mu \mathrm{m}$ and less). Such ultrafine PM can penetrate the respiratory system of people and be transported to other parts of the human body. They can cause widespread inflammation. PM can also be toxic. They may contain polycyclic aromatic hydrocarbons (for example benzene) which have cancerogenic properties, heavy metals and their components etc. PM can also generate primary organic aerosols (European Commission, 2016).

\section{POSSIBILITIES OF DECREASING THE BOIL-OFF FROM CARGO TANKS}

The main source of gas on LNG carriers is boil-off gas from cargo tanks. Due to low temperatures of carrying LNG (about $-161.5^{\circ} \mathrm{C}$ ) and heat transfer from the environment spaces to the cargo tanks the methane, in state of liquid, is vaporized. The rate of vaporization is limited by the regulations. It should be less than $0.25 \%$ of tank capacity per one day. Utilization of atmospheric tanks need cryogenic tanks for methane. Very low critical temperature for methane $\left(-82.56^{\circ} \mathrm{C}\right)$ and rather high critical pressure $(4.7 \mathrm{MPa})$ makes problem for possibility of methane liquefaction and transport in state of liquid. The vaporizing ratio (VR) for methane is about 660 , it means that from $1 \mathrm{~m}^{3}$ of liquid during vaporization it will be received $660 \mathrm{~m}^{3}$ of gas at normal condition $\left(0^{\circ} \mathrm{C}\right.$ and 1.013 bar) (for LNG the VR is about 600 ).

The rate of vaporization may be decreased by cargo tanks thermal insulation and as a result in decreasing the total heat transfer coefficient for the cargo tank wall $k$ (Fig. 1). It is still tried to find better insulations with lower heat conductivity. The cooling plant on a gas carrier is constructed and calculated for thermal leakage (boil-off) from cargo tanks and system when the ship is new. Insulation is exposed for ageing, wear and tear and will in time be reduce if maintenance of insulation is not kept (IMO, 2009).

Increased boil-off will occur if the insulation on cargo tanks and pipelines reduces. It involves removal of more heat (more boil-off) from the cargo tanks. Additionally the time used to cool the cargo and needed energy for liquefaction increase. 


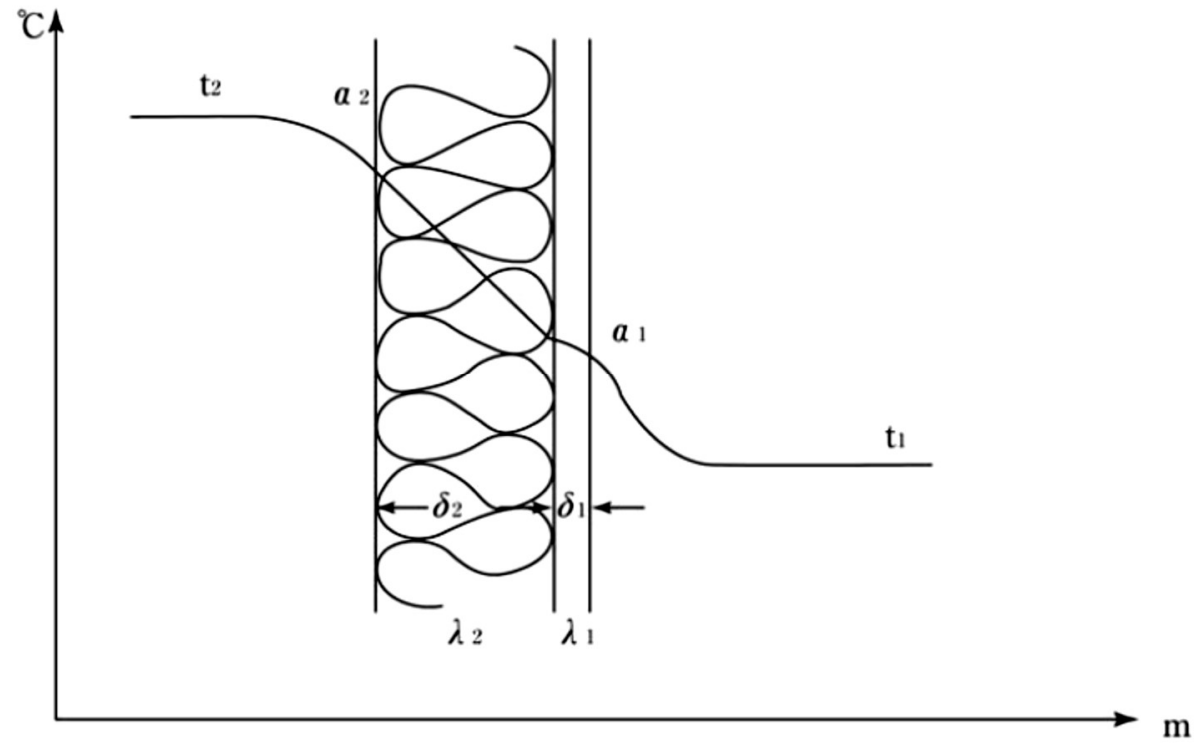

Source: IMO, 2009

Fig. 1. Heat flow through insulated wall of cargo tank.

where:

$\mathrm{t}_{1}$ - temperature of liquefied natural gas $\left[{ }^{\circ} \mathrm{C}\right]$;

$\mathrm{t}_{2} \quad$ - hold space gas temperature $\left[{ }^{\circ} \mathrm{C}\right]$;

$\delta_{1} \quad$ - the tank wall thickness [m];

$\delta_{2} \quad$ - thermal protection wall thickness [m];

$\lambda_{1}$ - thermal conductivity of tank shell $\left[\mathrm{kJ} /\left(\mathrm{m} \cdot \mathrm{h} \cdot{ }^{\circ} \mathrm{C}\right)\right]$;

$\lambda_{1}$ - thermal conductivity of thermal protection $\left[\mathrm{kJ} /\left(\mathrm{m} \cdot \mathrm{h} \cdot{ }^{\circ} \mathrm{C}\right)\right]$;

$\alpha_{1} \quad$ - heat transfer coefficient of liquefied natural gas and tank wall $\left[\mathrm{kJ} /\left(\mathrm{m}^{2} \cdot \mathrm{h} \cdot{ }^{\circ} \mathrm{C}\right)\right]$;

$\alpha_{2}$ - heat transfer coefficient of surface of thermal protection and hold space gas $\left[\mathrm{kJ} /\left(\mathrm{m}^{2} \cdot \mathrm{h} \cdot{ }^{\circ} \mathrm{C}\right)\right]$;

$k \quad$ - overall heat transfer coefficient for the cargo tank wall $\left[\mathrm{kJ} /\left(\mathrm{m}^{2} \cdot \mathrm{h} \cdot{ }^{\circ} \mathrm{C}\right)\right]$;

F - surface of cargo tank [m²];

$\mathrm{R}_{\mathrm{CH} 4}$ - methane heat of vaporization at ambient pressure $[\mathrm{kJ} / \mathrm{kg}]$.

Data for calculation the overall heat transfer coefficient for the cargo tank wall:

$\mathrm{t}_{1}=-162^{\circ} \mathrm{C}, \quad \mathrm{t}_{2}=35^{\circ} \mathrm{C}, \quad \delta_{1}=0.04 \mathrm{~m}, \quad \delta_{2}=0.3 \mathrm{~m}$,

$\lambda_{1}=731,5 \mathrm{~kJ} /\left(\mathrm{m} \cdot \mathrm{h} \cdot{ }^{\circ} \mathrm{C}\right)\left(175 \mathrm{kcal} /\left(\mathrm{m} \cdot \mathrm{h} \cdot{ }^{\circ} \mathrm{C}\right)\right)$,

$\lambda_{2}=0.1254 \mathrm{~kJ} /\left(\mathrm{m} \cdot \mathrm{h} \cdot{ }^{\circ} \mathrm{C}\right)\left(0.03 \mathrm{kcal} /\left(\mathrm{m} \cdot \mathrm{h} \cdot{ }^{\circ} \mathrm{C}\right)\right)$,

$\alpha_{1}=836 \mathrm{~kJ} /\left(\mathrm{m}^{2} \cdot \mathrm{h} \cdot{ }^{\circ} \mathrm{C}\right), \alpha_{2}=12.54 \mathrm{~kJ} /\left(\mathrm{m}^{2} \cdot \mathrm{h} \cdot{ }^{\circ} \mathrm{C}\right), \mathrm{F}=25,000 \mathrm{~m}^{2}, \mathrm{R}_{\mathrm{CH} 4}=647.9 \mathrm{~kJ} / \mathrm{kg}$.

The resistance of heat transmission can be calculating by the following equation (1):

$$
\frac{1}{\mathrm{k}}=\frac{1}{\alpha_{1}}+\frac{\delta_{1}}{\lambda_{1}}+\frac{\delta_{2}}{\lambda_{2}}+\frac{1}{\alpha_{2}}
$$

received:

$$
\mathrm{k}=0.418 \mathrm{~kJ} /\left(\mathrm{m}^{2} \cdot \mathrm{h} \cdot{ }^{\circ} \mathrm{C}\right)\left(0.1 \mathrm{kcal} /\left(\mathrm{m}^{2} \cdot \mathrm{h} \cdot{ }^{\circ} \mathrm{C}\right)\right) .
$$

The overall heat transfer to cargo tanks is:

received:

$$
\mathrm{Q}=\mathrm{k} \cdot \mathrm{F} \cdot\left(\mathrm{t}_{2}-\mathrm{t}_{1}\right)
$$

$$
\mathrm{Q}=2058.7 \mathrm{MJ} / \mathrm{h} \text {. }
$$

Calculating the daily rate of boil-off:

$$
\text { boil }- \text { off }=\frac{Q \times 24}{R}
$$

received:

$$
\text { boil }- \text { off }=100 \mathrm{t} / \text { day. }
$$

Such evaporation rate can be too high for consuming as a fuel in vessel's energetic plants. The overage should be liquefied again and as a liquid should be transfer to cargo tanks.

The rate of vaporization may be decreased through the increasing of the cargo tank capacity. It was built (for Qatar Gas) spherical tanks with 46 m of internal diameter. The volume of one tank 
is $51000 \mathrm{~m}^{3}$ and the tank surface about $6.647 \mathrm{~m}^{2}$. It means that during increasing the size of tank decreasing the ratio surface $(\mathrm{S})$ to volume $(\mathrm{V})$. For spherical tanks it will be as:

$$
\frac{\mathrm{S}}{\mathrm{V}}=\frac{3}{\mathrm{R}}
$$

where:

$R \quad$ - the radius of spherical tank [m].

It was received (for $R_{1}=3 \mathrm{~m}$ and $\mathrm{R}_{2}=23 \mathrm{~m}$ ) respectively:

$$
\frac{\mathrm{s}}{\mathrm{V}}=1 \quad \text { and } \quad \frac{\mathrm{s}}{\mathrm{V}}=0.13 \text {. }
$$

The quantity of heat transfer depends linearly to the surface of cargo tank but the rate of vaporization depends on the ratio surface $(\mathrm{S})$ to volume $(\mathrm{V})$. Such a way it was received the rate of vaporization below $0.15 \%$ of cargo tank capacity per one day of voyage. The spherical tank of $46 \mathrm{~m}$ of diameter is presented on Fig. 2. It should be remembered about the additional problems with building such big cargo tanks for example: the strength on cargo mass and forces from hull on cargo containment.

Some important advices for maintaining the cargo tank insulation (IMO, 2009):

- held the atmosphere in hold spaces dry by drying the atmosphere regularly, use dry inert gas, dry carbon dioxide or nitrogen, if possible;

- control the cargo tank insulation regularly. Areas with ice or humidity indicate thermal loss. Note these areas with spray paint to easier locate the areas when these need repairing and repair;

- control external insulation regularly and repair wrecked water barrier plates immediately. Areas with ice or humidity indicate thermal loss. Note the areas with spray painting in order to easily locate when need of repairing and repair;

- at all times, have necessary materials to repair wrecked insulation onboard, minimum materials to repair damages on water barrier. As some of the insulation materials have limited operating time, the stock onboard must be adjusted to the expected consumption next month;

- before adding new insulation in place, corrosion and pitting must be controlled. The steel must be protected from corrosion before new insulation is put on place.

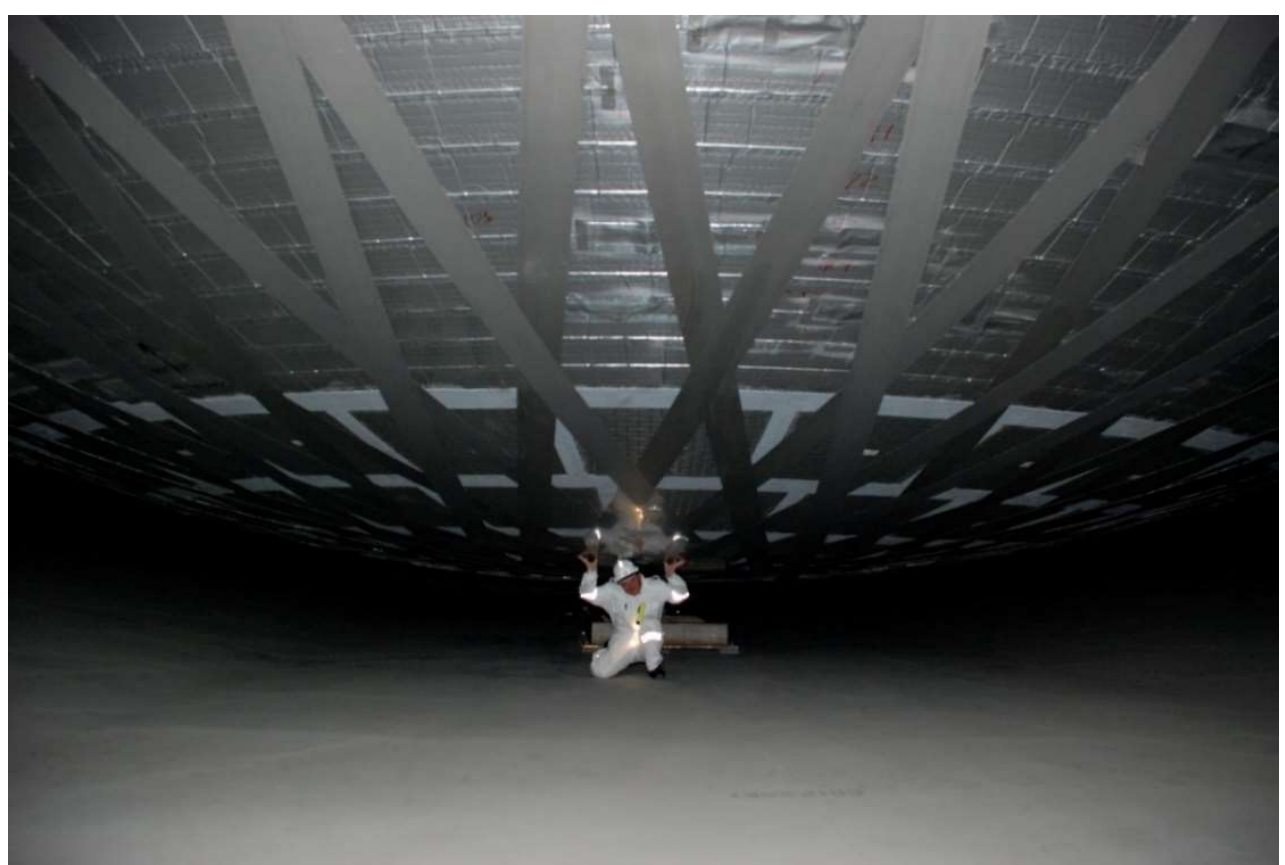

Fig. 2. Spherical tank of 46m diameter on LNG carrier Arctic Discoverer. Source: own library

The condition of cargo tank insulation and external insulation is vital for the limitation of boil-off rate. 


\section{Re-LIQUEFACTION EQUIPMENT ON LNG VESSELS - COMPANDERS}

To minimize the slip on LNG carriers the re-liquefaction systems are installed. They are based on cooling systems which boil-off gas (mainly methane) is liquefied at ambient pressure in temperature about $-161.5^{\circ} \mathrm{C}$ by pre-cooled nitrogen gas at temperature about $-180^{\circ} \mathrm{C}$. If nitrogen liquefied at about $-195^{\circ} \mathrm{C}$ it will be dangerous for re-liquefied system due to the risk of clogging (freezing point of methane is $-183^{\circ} \mathrm{C}$ ).

At first the nitrogen is compressed to a pressure about $25 \mathrm{MPa}$ through multistage compressors with intercooling systems. Next the compressed nitrogen is expanded step by step (in intercoolers) to pressure about ambient reaches the temperature about $-180^{\circ} \mathrm{C}$. The nitrogen compressors and expanders have a name as companders (Fig. 3).

The methane recovery from gas to liquid needs a lot of energy (about $15-20 \%$ of methane heat value, it means that using methane as fuel for producing electric energy for re-liquefaction systems it would be liquefied about $80 \%$ of BOG taking from cargo tanks) (Mitsui OSK Lines, 2007).

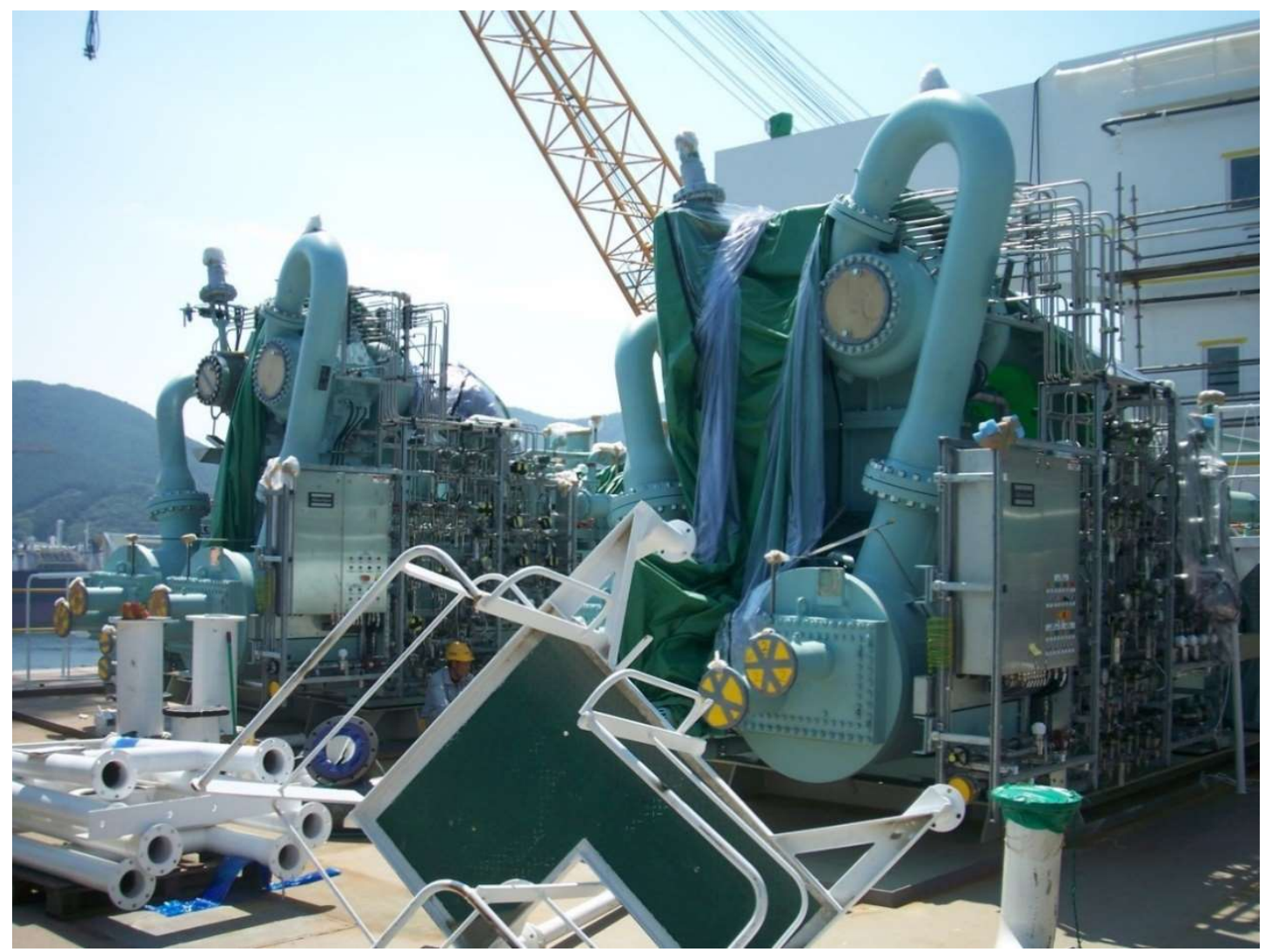

Fig. 3. Atlas Copco nitrogen compander (2 pieces) before installation.

Source: own library

\section{LEAKAGES FROM BUNKERING OPERATIONS}

LNG bunkering of gas-fueled vessels causes the methane leakage due to fuel hoses blow through before and after bunkering process. There is no re-liquefaction units, so in normal operation states, the rate of needed boil-off is reached through the forced evaporation (using heat from engine cooling medium). In case of long term stay with low energy demand the normal boil-off (without forced warming) may be too high for using as fuel. Due to the rise of pressure in fuel tanks over the safety relief valve setting the valves will open and the methane will go to the atmosphere. The partly solution is burning the boil-off. The carbon dioxide is produced that way.

Diesel engines working on diesel oils have a methane slip on the level 0.5-1 g/kWh. When working on gas due to misfires the slip may be bigger. An example of main engine gas injection system is presented on the Fig. 4. 


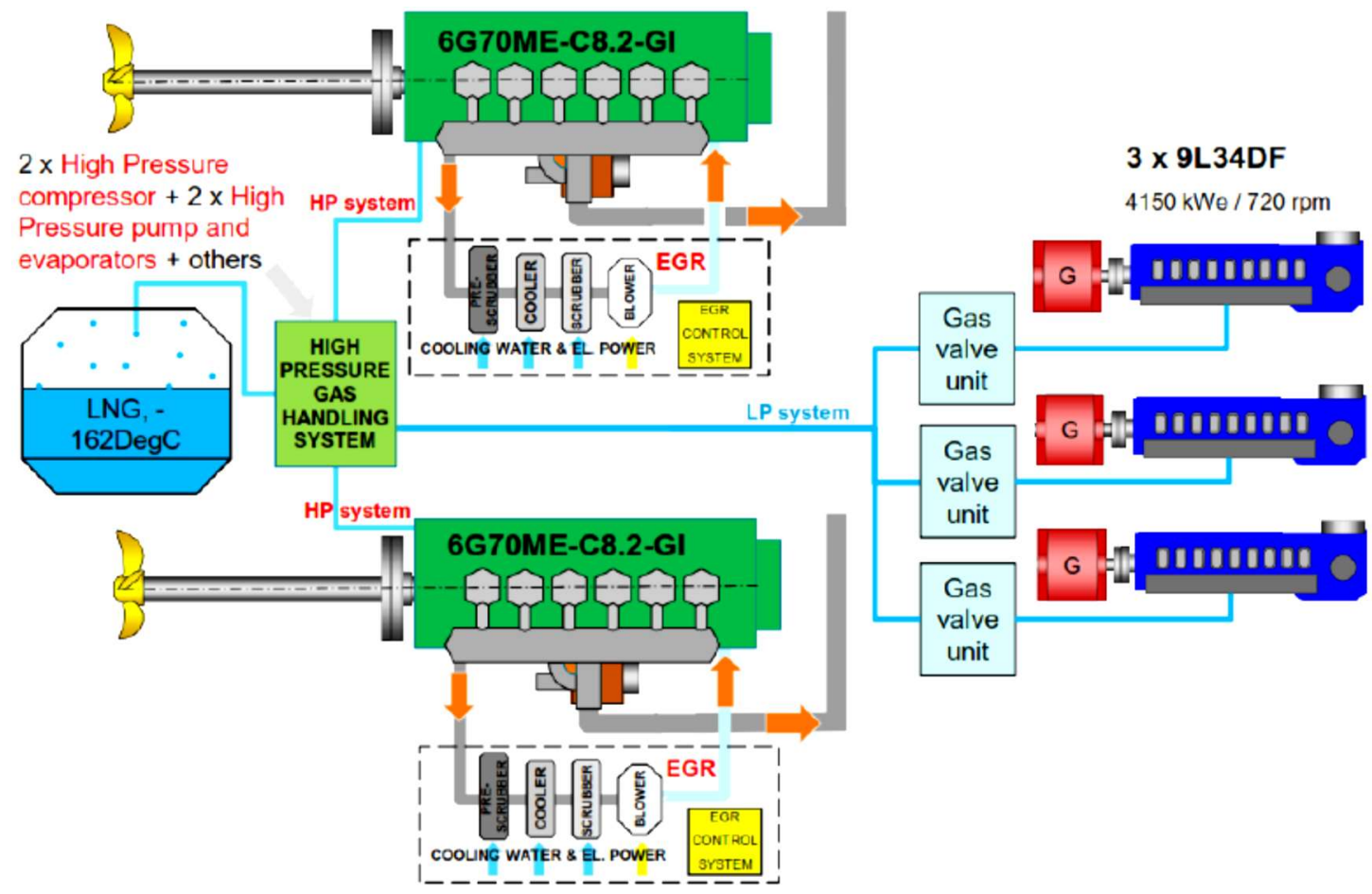

Source: Wärtsilä, 2017

Fig. 4. Main engine gas injection (MEGI) system.

It is possible to oxidize the hydrocarbons in exhaust gases but it needs rather high temperatures. For methane the oxidation requires over $540^{\circ} \mathrm{C}$, for heavier hydrocarbons do oxidize at lower temperatures (Contessi, 2013).

Methane leakage rates above 2-3\% would probably offset the environmental gains for natural gas. Recent studies have shown methane leakage rates that is much higher than average industry estimates. It is probably on the level 5-9\% (Morgan Stanley, 2013).

There are some propositions of technologies available for reducing methane leakage during mining-output like plunger lifts, replace high-bleed pneumatics with low-bleed equivalents, leak detection and repair (World Ocean Review, 2014, Morgan Stanley, 2013) but it needs additional investment costs.

\section{PRIMARY AND SECONDARY POSSIBILITIES OF DECREASING THE METHANE SLIP}

It is a necessary to find out methods of methane slip reduction. For dual fuel (DF) engines or gas engines there are following propositions (Contessi, 2013, Baekert, 2016):

- proper main fuel injection timing;

- boost pressure;

- proper charge air temperature;

- opened air by pass valve at part load;

- skip firing;

- minimized dead volumes;

- change the compression ratio;

- pilot fuel optimization in DF engines;

- using the exhaust gas recirculation (EGR) valves.

The secondary methods are: using the sandbed and oxidation catalyst.

\section{CONCLUSION}

It is known that LNG can contribute to a significant reduction of air pollution from shipping in compare to marine fuel oils. It shows that there are issues with LNG requiring further investigation, especially with methane slip having an impact on the climate. 
It should be estimated the methane leakage. If it rates above $2-3 \%$ would probably offset the environmental gains for natural gas. Recent studies have shown methane leakage rates that is much higher than it was estimated.

It should be discussed on expert forums, including the International Maritime Organization (IMO), the European Sustainable Shipping Forum and Society for Gas as a Marine Fuel.

Low-sulfur fuels in conjunction with particulate filters and catalysts are available, cost-effective and proven technologies for pollutant reduction. However, for example the Naturschutzbund Deutschland (NABU) rejects the favoring of LNG versus other available alternatives.

Further research and development is needed.

\section{REFERENCES}

Mitsui OSK Lines Ltd., (2007). LNG Carrier Operation Technology Text. Hamworthy Gas Systems AS, (2006). QGII QFLEX Operational Manual.

Cargo Operating Manual, (2008).

McGuire and White, (2008). Liquefied Gas Handling Principles on Ships and in Terminals, SIGGTO, Witherby Publishers.

IMO, (2009). Gas Tanker Advanced Course.

LNG Custody Transfer Handbook, (2001). G.I.I.G.N.L. DS TML/Z-CG-2001.

European Commission, (2016). Methane emissions from LNG-powered ships higher than current marine fuel oils, Science for Environment Policy.

Corbett J.J., et al, (2015). Methane Emissions from Natural Gas Bunkering Operations in the Marine Sector: A Total Fuel Cycle Approach, prepared for: US Department of Transportation Maritime Administration.

Contessi C., (2013). Gas Engine Emissions, Wärtsilä Dual Engines, Wärtsilä.

Wärtsilä, (2017). Tri-fuel Engines, [online] Available at: http://www.intertanko.com/Documents/ISTEC\%20LNG\%20WG\%202015/Maran\%20\%20TRI\%20FUEL\%20ENGINES.pdf [Accessed: 12 June 2017].

Baekert M., (2016). LNG as fuel for shipping, Norsk Gassforum, Brussels, DNVGL.

World Ocean Review, (2014). Marine Resources - Opportunities and Risks, 3/2014.

Morgan Stanley Research, (2013). Natural Gas as a Transportation Fuel Energy.

Mokhatab S., et al, (2015). Handbook of natural gas transmission and processing: principles and practices, Elsevier.

DeLancey G., (2013). Principles of chemical engineering practice, Wiley.

Proceedings of the ASME $35^{\text {th }}$ International Conference on Ocean, Offshore and Arctic Engineering, (2016). Polar and arctic sciences and technology. 